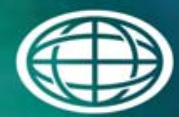

Savannah River

National Laboratory

\title{
Hydraulics and Mixing Evaluations for NT-21/41 Tanks
}

Si Young Lee

Oliver L Barnes, Jr

October 2014

SRNL-STI-2014-00513 


\section{DISCLAIMER}

This work was prepared under an agreement with and funded by the U.S. Government. Neither the U.S. Government or its employees, nor any of its contractors, subcontractors or their employees, makes any express or implied:

1. warranty or assumes any legal liability for the accuracy, completeness, or for the use or results of such use of any information, product, or process disclosed; or

2. representation that such use or results of such use would not infringe privately owned rights; or

3. endorsement or recommendation of any specifically identified commercial product, process, or service.

Any views and opinions of authors expressed in this work do not necessarily state or reflect those of the United States Government, or its contractors, or subcontractors.

Printed in the United States of America

Prepared for U.S. Department of Energy 
Keywords: Tank Mixing, Pump

Circulation, Hydraulic Head

Retention: Permanent

\section{Hydraulic and Mixing Evaluations for NT-21/41 Tanks}

Si Young Lee

Oliver L. Barnes, Jr

October 2014

Prepared for the U.S. Department of Energy under contract number DE-AC09-08SR22470.

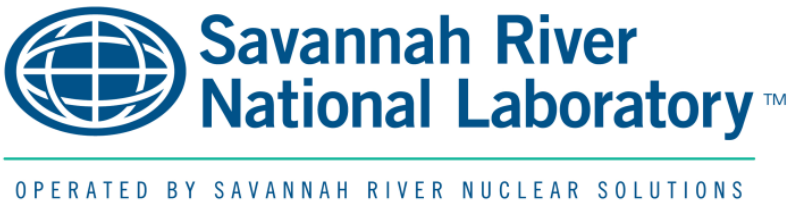




\section{EXECUTIVE SUMMARY}

The hydraulic results demonstrate that pump head pressure of 20 psi recirculates about 5.6 liters/min flowrate through the existing 0.131 -inch orifice when a valve connected to NT-41 is closed. In case of the valve open to NT-41, the solution flowrates to HB-Line tanks, NT-21 and NT-41, are found to be about $0.5 \mathrm{lpm}$ and $5.2 \mathrm{lpm}$, respectively.

The modeling calculations for the mixing operations of miscible fluids contained in the HB-Line tank NT-21 were performed by taking a three-dimensional Computational Fluid Dynamics (CFD) approach. The CFD modeling results were benchmarked against the literature results and the previous SRNL test results to validate the model. Final performance calculations were performed for the nominal case by using the validated model to quantify the mixing time for the HB-Line tank. The results demonstrate that when a pump recirculates a solution volume of 5.7 liters every minute out of the 72 -liter tank contents containing two acid solutions of $2.7 \mathrm{M}$ and $0 \mathrm{M}$ concentrations (i.e., water), a minimum mixing time of 1.5 hours is adequate for the tank contents to get the tank contents adequately mixed. In addition, the sensitivity results for the tank contents of 8 $\mathrm{M}$ existing solution and $1.5 \mathrm{M}$ incoming species show that the mixing time takes about 2 hours to get the solutions mixed. 


\section{TABLE OF CONTENTS}

LIST OF TABLES ....................................................................................... vii

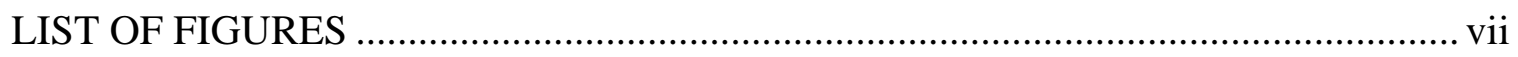

LIST OF ABBREVIATIONS .............................................................................. ix

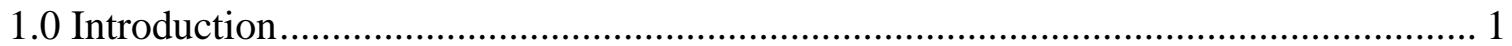

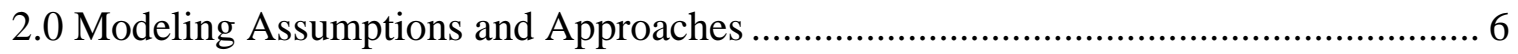

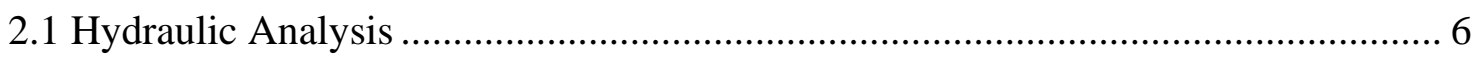

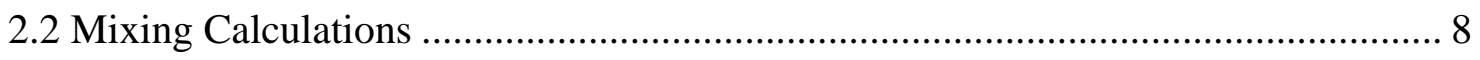

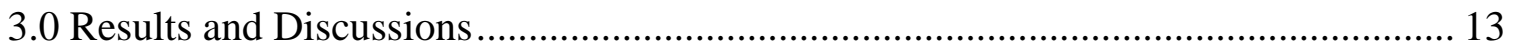

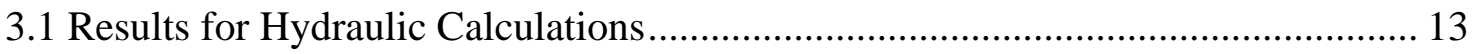

3.2 Results for Mixing Performance Calculations.................................................. 13

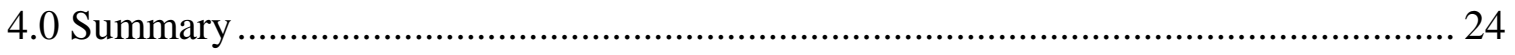

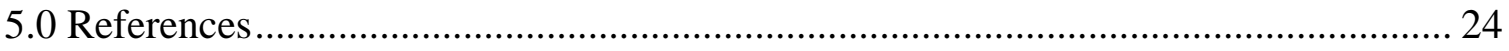




\section{LIST OF TABLES}

Table 1. Modeling conditions used for the hydraulic analysis ................................ 5

Table 2. CFD modeling conditions used for the mixing analysis.............................. 11

Table 3. Results for the modeling cases considered for the hydraulic analysis.............13

Table 4. Test conditions and literature mixing times [Ref. 3] for transient CFD

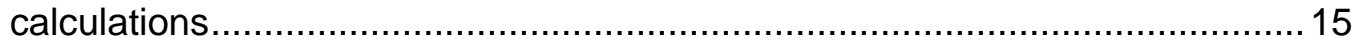

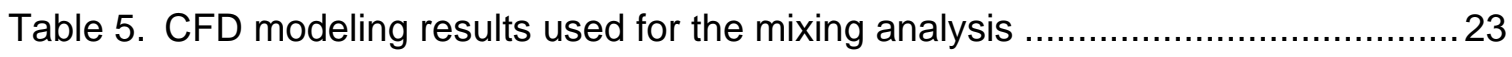

\section{LIST OF FIGURES}

Figure 1. Flow diagram for HB-Line tanks, NT-21 and NT 41 (Numerical number is a node number referred to as a location identifier.) ...................................... 2

Figure 2. Geometrical dimensions for NT-21.

Figure 3. A modeling geometry used for species mixing analysis of HB-Line NT-21 tank

Figure 4. Computational meshes for the NT-21 tank mixing analysis ( $1.2 \times 10^{5}$ meshes)

Figure 5. Initial mass fractions of the species and bulk fluids inside the NT-21 tank used for the mixing analysis

Figure 6 Tank A, geometry for the demonstration runs based on two different approaches of transient flow pattern and species transport calculations........ 15

Figure 7. Fully developed flow patterns used as the initial flow conditions for the transient transport calculations using tracer species .....

Figure 8. Lagrangian flow path lines from jet inlet to tank exit for fully developed flow circulation inside a tank during blending .

Figure 9. Comparison of transient time snapshots for flow patterns of species concentration at vertical central plane through the pump nozzle center line ( ${ }^{\star}$ Non-dimensionalized by equilibrium species concentration of $3.02 \times 10^{-4}$; literature blending time results $=32$ seconds)

Figure 10. Benchmarking results of theoretical tank blending time compared to experimental test results [6]

Figure 11. Circulation flow patterns near flow inlet and exit regions at 90 min. transient time. 
Figure 12. Flow velocity distributions for the central plane at 90 min. transient time $\ldots . . .21$

Figure 13. Flow turbulent intensity distributions for the central plane at $90 \mathrm{~min}$. transient time........

Figure 14. Transient non-dimensional mass fractions for Nominal case. 22

Figure 15. Transient species mass fractions during the mixing period (Nominal case). 23 


\section{LIST OF ABBREVIATIONS}

\begin{tabular}{|c|c|}
\hline A & Area \\
\hline C & Concentration or constant for equation \\
\hline $\mathrm{C}_{\mathrm{eq}}$ & Equilibrium concentration \\
\hline D & Tank diameter \\
\hline$D_{v}$ & Molecular diffusion coefficient \\
\hline$d_{h}$ & Hydraulic diameter \\
\hline$d_{0}$ & Pump nozzle diameter \\
\hline$E$ & Kinetic energy \\
\hline$f$ & Fanning friction factor \\
\hline g & Gravitational acceleration \\
\hline $\mathrm{H}$ & Hydraulic height \\
\hline I & Turbulence intensity \\
\hline$\vec{J}_{v}$ & Diffusion flux of tracer species \\
\hline$K$ & Frictional loss factor \\
\hline$k$ & Turbulent kinetic energy per unit mass \\
\hline $\mathrm{L}$ & Jet length or maximum integral length scale \\
\hline $\mathrm{p}$ & Pressure \\
\hline$\Delta p$ & Pressure drop \\
\hline$q$ & Volumetric flow rate \\
\hline $\mathrm{Re}$ & Reynolds number \\
\hline r & Local radial distance of turbulent jet region \\
\hline$S_{V}$ & Source term of tracer species \\
\hline $\mathrm{t}$ & Time \\
\hline $\mathrm{Sc}_{\mathrm{t}}$ & Turbulent Schmidt number (= Ratio of momentum to mass diffusion) \\
\hline$t_{m}$ & Mixing time \\
\hline$U_{0}$ & Pump exit velocity \\
\hline u & Velocity in the $x$-direction \\
\hline u' & Turbulent velocity in the $\mathrm{x}$-direction \\
\hline$V$ & Mean flow velocity magnitude \\
\hline $\mathrm{v}$ & Velocity in the y-direction \\
\hline$v^{\prime}$ & Turbulent velocity in the y-direction \\
\hline $\mathrm{x}$ & Local distance along the $x$-axis \\
\hline$Y_{v}$ & Local mass fraction of tracer species \\
\hline W & Velocity in the z-direction \\
\hline$w^{\prime}$ & Turbulent velocity in the z-direction \\
\hline$\varepsilon$ & Turbulent energy dissipation rate per unit mass \\
\hline$\varepsilon_{V}$ & Turbulent energy dissipation rate per unit volume \\
\hline$\rho$ & Fluid density \\
\hline$\lambda$ & Turbulent length scale \\
\hline$\mu_{t}$ & Turbulent dynamic viscosity $\left(=\rho v_{t}\right)$ \\
\hline$\tau_{w}$ & Wall shear stress \\
\hline$\Delta$ & Difference \\
\hline$\nabla$ & Gradient \\
\hline$v$ & Kinematic viscosity \\
\hline$v_{\mathrm{t}}$ & Turbulent eddy diffusion coefficient \\
\hline CFD & Computational Fluid Dynamics \\
\hline FLUENT & CFD software code \\
\hline
\end{tabular}




\subsection{Introduction}

The HB-Line Engineering Organization requested that Savannah River National Laboratory (SRNL) evaluate the methods to mix and blend the solution contents of the NT-21 tank to ensure the tank contents are properly mixed when the solution fluid is recirculated by a hydraulic pump through the flow loop of the tank. This work focuses on the estimate of hydraulic recirculation flowrate and mixing time of two miscible liquids due to the hydraulic recirculation driven by a pump, while ensuring that the solutions are mixed adequately.

The work scope described here consists of two areas to investigate two modeling studies. One area is to estimate the hydraulic flowrate of solution liquid driven by the pump head of 45 feet $(\sim 20 \mathrm{psi})$ through the flow circulation loop connected to two HB-Line tanks, NT-21 and NT-41, as shown in Fig. 1. The other one is to assess the operational time to mix and blend the solution contents of the blend tank to ensure the contents are properly mixed before they are transferred from the blend tank such as NT-21 to the NT-41 tank. The modeling calculations for estimate of the mixing time are performed by using the 95\% homogeneity criterion for the entire liquid domain of the tank. For the work, a hydraulic flow system connected to the NT-21 tank is comprised of 1 -inch and 0.402 -inch pipes, two valves, one orifice, 10 elbows, and one T-junction. The fluid flow of 5.7 liters $/ \mathrm{min}$ is recirculated by a pump through the piping loop during the nominal conditions. The tank contents in NT-21 consist of two different forms of fluids. One fluid is heavier than the other due to different acid molarities.

The circulation loops and tank dimensions used for the flowrate evaluations are schematically presented in Figs. 1 and 2. Prior to the transfer of the NT-21 contents to NT41 , the tank contents are supposed to be adequately mixed by the flow recirculation driven by the hydraulic pump head with Valve 1 closed so that the transfer flow to NT-41 is blocked for the mixing operation. The mixing tank, NT-21, has a thin slab tank of 3.25 inches wide and 63.25 inches long as shown in Fig. 2. After the solutions in NT-21are properly mixed, most of them will be transferred to NT-41 by opening Valve 1 . In case of the valve opening, the orifice located between the points 21 and 22 in Fig. 1 controls the flowrate returning to NT-21 in terms of the pressure loss. The recirculated flowrate is determined by the first work scope of the hydraulic analysis.

The cases considered for the hydraulic analysis are:

- Case-1: Estimate of the circulation flowrate for orifice diameter 0.131 inches and Valve 1 closed.

- Case-2: Estimate of the circulation flowrate for orifice diameter 0.131 inches and Valve 1 open.

- Case-3: Estimate of the circulation flowrate for orifice diameter 0.25 inches and Valve 1 closed.

- Case-4: Estimate of the circulation flowrate for orifice diameter 0.25 inches and Valve 1 open.

Tank fluid is pumped out by the exit pipe with 1 inch diameter located at the bottom floor of the tank side, and it is discharged back to the tank thorough the $60^{\circ}$ elbow located at 0.25 inches above the tank floor. The tank contents are dispersed and mixed mainly by the 
recirculation flow established by the hydraulic head through the submerged elbow pipe of 0.402 inches in diameter. The detailed dimensions and geometrical shape of the tank NT21 are shown in Fig. 2.

The hydraulic calculations for the circulation loops connected to NT-21 and NT-41 are made by using Microsoft Excel software. Modeling conditions for the hydraulic estimate are shown in Table 1. All mixing calculations for the NT-21 tank are performed by a three-dimensional Computational Fluid Dynamics (CFD) approach coupled with species transport equation. The modeling domain and geometry of the mixing tank are shown in Fig. 3.

The CFD modeling results are benchmarked against the literature results [2] and the previous SRNL test results [5] to validate the model. Final performance calculations were performed by using the validated model to quantify the mixing time for the HB-Line tank NT21 and to demonstrate the adequacy of hydraulic flowrate driven by one recirculation pump to get the tank contents well mixed.

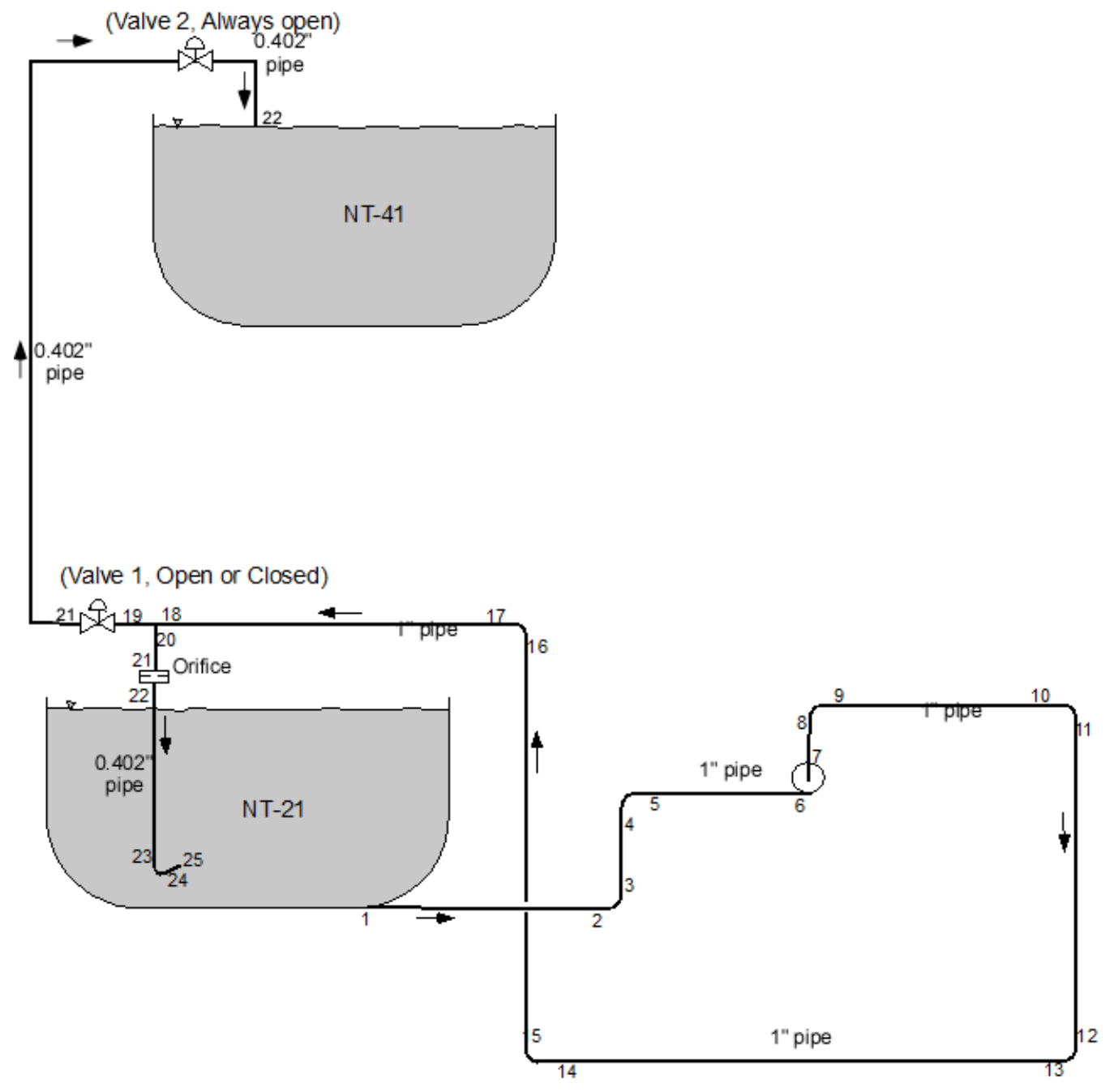

Figure 1. Flow diagram for HB-Line tanks, NT-21 and NT-41 (Numerical number is a node number referred to as a location identifier.) 
Tank wall boundary
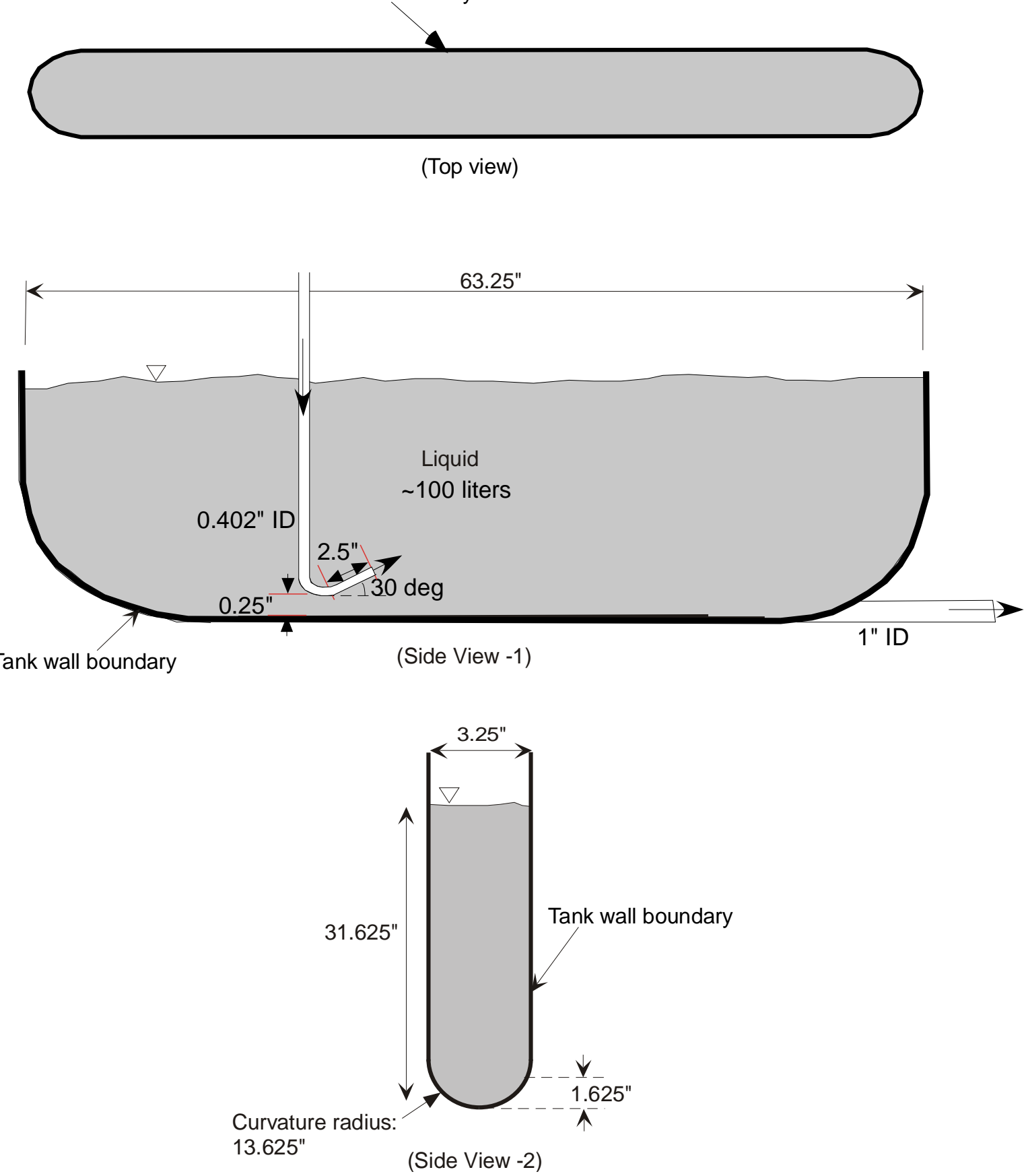

Figure 2. Geometrical dimensions for NT-21. 
SRNL-STI-2014-00513

Revision 0

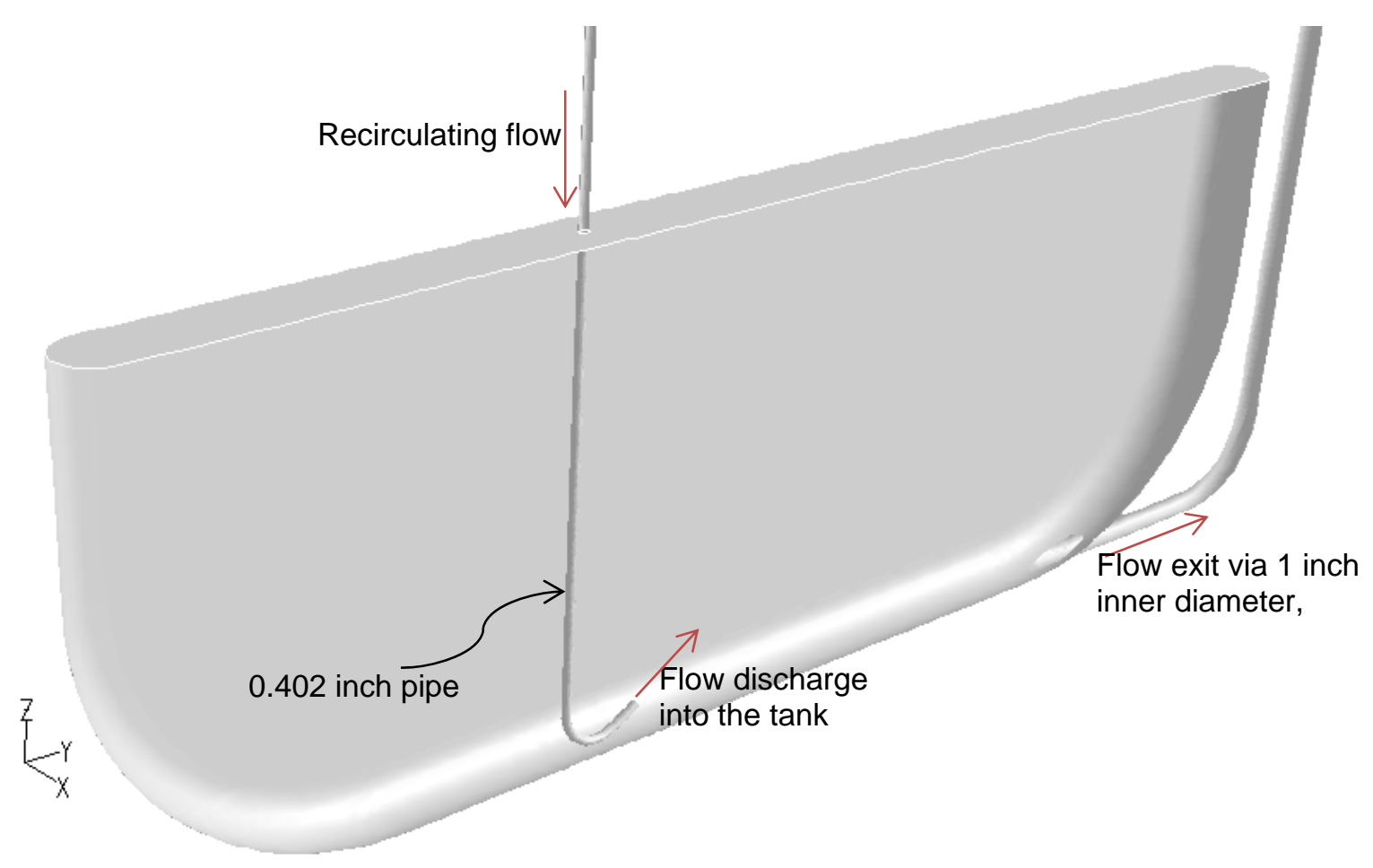

Figure 3. A modeling geometry used for species mixing analysis of HB-Line NT-21 tank 
Table 1. Modeling conditions used for the hydraulic analysis

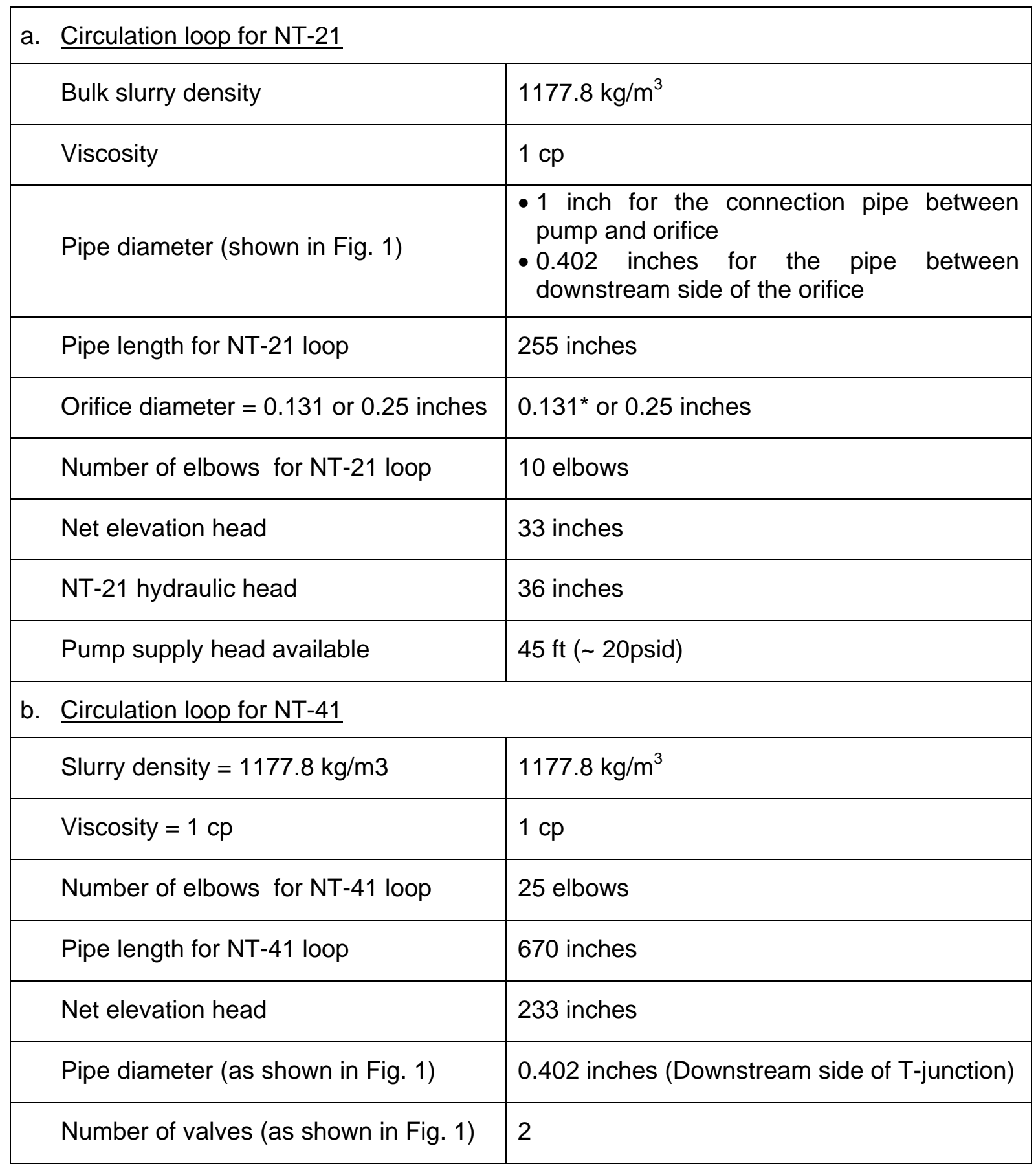

Note:*Nominal case 


\subsection{Modeling Assumptions and Approaches}

\subsection{Hydraulic Analysis}

The present calculation uses one-dimensional steady-state approach for a given pump flow boundary. The modeling assumptions are made as follows:

- The connection pipe is completely filled with flowing fluid without plugging. The 20-psi pump head corresponding to hydraulic head of 45 feet is supplied to the circulation loop, and the fluid exits the pipe as a free jet inside the tanks with a free surface, NT-21 and NT-41.

- No leakage is allowed within circulation loop.

- The fluid is a single-phase incompressible fluid, assuming that slurry fluid is homogeneously mixed and isothermal.

- Slurry follows Newtonian fluid behavior.

The governing equation can be derived from one-dimensional steady-state integral momentum equations for incompressible flow. That is,

$$
\begin{aligned}
0 & =\int\left\{\left(\frac{\mathrm{dp}}{\mathrm{dx}}\right)_{\text {friction }}\right\} \mathrm{dx}+\int\left\{\left(\frac{\mathrm{dp}}{\mathrm{dx}}\right)_{\text {acceleration }}\right\} \mathrm{dx}+\int\left\{\left(\frac{\mathrm{dp}}{\mathrm{dx}}\right)_{\text {gravity }}\right\} \mathrm{dx}+(\Delta \mathrm{P})_{\text {Pump }} \\
& =-\left(\frac{\mathrm{P}_{\mathrm{w}}}{\mathrm{A}}\right) \tau_{\mathrm{w}}+0-\rho \mathrm{gH}+(\Delta \mathrm{P})_{\text {Pump }} \\
& =-\left(\sum_{\mathrm{i}=1}^{\mathrm{I}} \Delta \mathrm{P}_{\mathrm{i}-\mathrm{j}}\right)_{\text {Friction }}-\left(\sum_{\mathrm{i}=1}^{\mathrm{J}} \Delta \mathrm{P}_{\mathrm{i}-\mathrm{j}}\right)_{\text {Elevation }}+(\Delta \mathrm{P})_{\text {Pump }}
\end{aligned}
$$

In eq. (1) $P_{w}$ and $A$ are wetted wall area and flow area of the pipe, respectively. The parameter $\tau_{w}$ and $H$ in the eq. (1) are wall shear stress and elevation height for the flow system. The wall shear stress can be expressed in terms of a friction factor and hydraulic mean diameter $\left(d_{h}\right)$. The resulting equation consists of total frictional pressure loss $\Delta P_{\text {Friction, }}$,

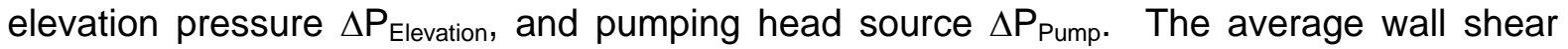
stress is

$$
\tau_{w}=\frac{1}{2} f \rho u^{2}
$$

In eq. (2) $f$ is called Fanning friction factor and it is obtained from an empirical correlation. The ratio of the wetted perimeter $\left(P_{w}\right)$ to flow area $(A)$ for a given pipe becomes

$$
\frac{\mathrm{P}_{\mathrm{w}}}{\mathrm{A}}=\frac{\pi \mathrm{d}}{0.25 \pi \mathrm{d}_{\mathrm{h}}{ }^{2}}=\frac{4}{\mathrm{~d}_{\mathrm{h}}}
$$

Using eqs. (1), (2), and (3), the resulting equation can be written in terms of volumetric flowrate (q) and hydraulic head $(\mathrm{H})$, which is equivalent to net elevation of the fluid between the inlet and the exit. Elevation head pressure in eq. (1) is dependent on net elevation difference $\Delta \mathrm{H}$ between the supply and the discharge exit. That is

$$
\Delta \mathrm{P}_{\text {Elevation }}=\rho g(\Delta \mathrm{H})
$$

Total frictional pressure loss for the loop connected to the tanks, NT-21 and NT-41, becomes 


$$
\Delta \mathrm{P}_{\text {Friction }}=\Delta \mathrm{P}_{\text {pipe }}+\Delta \mathrm{P}_{\text {elbow }}+\Delta \mathrm{P}_{\mathrm{T}-\text { jun }}+\Delta \mathrm{P}_{\text {orifice }}
$$

When volumetric flowrate $q$ is expressed in terms of hydraulic diameter $\left(d_{h}\right)$ and pipe length between the nodes $\mathrm{i}$ and $\mathrm{j}\left(\mathrm{L}_{\mathrm{ij}}\right)$ as indicated in Fig. 1, the frictional pressure drop between the nodes $\mathrm{i}$ and $\mathrm{j}$ for the pipe region becomes

$$
\left(\Delta \mathrm{P}_{\mathrm{i}-\mathrm{j}}\right)_{\text {pipe }}=\frac{8}{\pi^{2}}(4 \mathrm{f})\left(\frac{\mathrm{L}_{\mathrm{ij}}}{\mathrm{d}_{\mathrm{h}}^{5}}\right) \rho \mathrm{q}^{2}
$$

The frictional pressure drop through elbow component is expressed in terms of hydraulic diameter $\left(d_{h}\right)$ and pipe length between the nodes $i$ and $j\left(L_{i j}\right)$, the frictional pressure drop for flowrate $q$ through the elbow component becomes

$$
(\Delta \mathrm{P})_{\text {elbow }}=\frac{8}{\pi^{2}}\left(\frac{\mathrm{K}_{\text {elbow }}}{\mathrm{d}_{\mathrm{h}}{ }^{4}}\right) \rho \mathrm{q}^{2}
$$

Frictional pressure drop through the T-junction becomes

$$
(\Delta \mathrm{P})_{\mathrm{T}-\mathrm{jun}}=\frac{8}{\pi^{2}}\left(\frac{\mathrm{K}_{\mathrm{T}-\mathrm{jun}}}{\mathrm{d}_{\mathrm{h}}{ }^{4}}\right) \rho \mathrm{q}^{2}
$$

Frictional pressure drop through the orifice becomes

$$
(\Delta \mathrm{P})_{\text {orifice }}=\frac{8}{\pi^{2}}\left(\frac{\mathrm{K}_{\text {Orifice }}}{\mathrm{d}_{\mathrm{h}}{ }^{4}}\right) \rho \mathrm{q}^{2}
$$

$\mathrm{K}_{\mathrm{j}}$ in the above equations represents flow resistance for $\mathrm{j}$ component of the loop in terms of friction factor and geometrical dimensions. For the calculation of flow resistance, the Fanning friction factor $(f)$ correlation is required. The flow resistance $(K)$ values for the flow direction changes and elbows etc. were provided by the literature [Crane, 1976, Idelchik et al., 1986].

The Fanning friction factor for turbulent flow (greater than 2,000 Reynolds number for the present work) is

$$
\mathrm{f}=\left(\frac{0.079}{\operatorname{Re}^{0.25}}\right)
$$

Reynolds number Re is given in terms of flowrate $q$ as follows:

$$
\operatorname{Re}=\left(\frac{4}{\pi}\right)\left(\frac{\rho}{\mu \mathrm{d}_{\mathrm{h}}}\right) \mathrm{q}
$$

When pump supply head through the flow loops to NT-21 and NT-41 is given, the governing equation is complete for estimating flowrate q by using eq. (1). 


\subsection{Mixing Calculations}

For the mixing analysis, a three-dimensional computational fluid dynamics (CFD) approach was taken to calculate flow velocity distributions for the modeling domain, and to estimate mixing time for two miscible liquids; such as, solution and acid, for HB-Line tank NT-21 as illustrated in Fig. 3. The results are benchmarked against both literature data and SRNL test data [2]. A commercial finite volume code, FLUENT, was used to create a full scale geometry file in a non-orthogonal mesh environment.

The prototypic model geometry was created on the computational domain by using the body-fitted coordinate system and structured multi-block grids. For the mixing performance analysis, the reference design conditions were considered as shown in Fig. 1 and Table 1. As shown in Table 2, the circulation flow of 5.7 liters $/ \mathrm{min}$ is jetted into the contents of a slab tank through the $60^{\circ}$ elbow pipe for the mixing. The same flowrate is pulled through the 1inch pipe exit installed at the tank floor of NT-21, and it is discharged back into the tank liquid through the 0.402-inch elbow pipe that is located about 0.25 inches above the tank floor. This elbow inlet is directed at a $30^{\circ}$ angle toward top liquid surface as shown in Figs 2 and 3. The hydraulic calculation results show that about 5.6 liters per minute is recirculated through NT-21 during the mixing period. This flow rate is very close to the nominal flowrate of 5.7 liters/min, which was used for the estimate of the mixing calculations. However, the mixing time change due to the difference between these two flowrates was found to be negligible from the mixing sensitivity analysis.

For the mixing calculations, the transient governing equations consist of one mass balance, three momentum equations along the Cartesian coordinate system, two turbulence transport equations for kinetic energy $(k)$ and dissipation rate $(\varepsilon)$, and one species transport. The equations were transiently solved by an iterative technique until the species concentrations of tank fluid were reached at equilibrium concentration within $1 \%$ relative error. For $\mathrm{C}_{\mathrm{eq}}$ the equilibrium concentration and $\mathrm{C}$ the transient concentration at a monitoring point, the $99 \%$ mixing time $t_{m}$ was defined by

$\mathrm{t}_{\mathrm{m}}=\left|\frac{\mathrm{C}-\mathrm{C}_{\mathrm{eq}}}{\mathrm{C}}\right|<0.01$

The present work used the assumptions as follows:

- Top tank liquid surface was assumed to be frictionless for computational efficiency, neglecting the detailed wave motion of the free surface. That behavior does not have a significant impact on the flow patterns inside the slurry region in a deep tank.

- The fluid properties of water or acid solution were evaluated at values to conservatively evaluate the system.

- The flow conditions for the pump operations are assumed to be fully turbulent since Reynolds numbers for typical operating conditions are in the range of $1 \times 10^{4}$ to 3.0 $\times 10^{4}$ based on the nozzle inlet conditions (0.402 inch inlet diameter).

- Inlet pipe was considered as major flow obstruction, assuming that detailed small objects attached to the inner wall of the tank have negligible impact on the mixing time due to flow recirculation

A standard two-equation turbulence model, the $\kappa-\varepsilon$ model [3], was used to capture the turbulent flow evolution driven by the blending circulation pump since the previous work [2, 
3] showed that the two-equation model predicts the flow evolution of turbulent jet in a large stagnant fluid domain with reasonable accuracy. This model specifies the turbulent or "eddy" viscosity $v_{t}$ by the empirical equation.

$v_{t}=\frac{\mu_{t}}{\rho_{f}}=\left(\frac{C_{\mu} k^{2}}{\varepsilon}\right)$

In Eq. (13), $C_{\mu}$ is an empirical constant. In the present calculations, $C_{\mu}$ is 0.09 [7]. Thus, the turbulent viscosity is computed by solving two transport equations for $k$ (turbulent kinetic energy), and $\varepsilon$ (rate of dissipation of turbulent energy).

From these two key parameters of $k$ and $\varepsilon$, a length scale $\left(k^{1.5} / \varepsilon\right)$, a timescale $(k / \varepsilon)$, a quantity of turbulent eddy diffusivity $\left(k^{2} / \varepsilon\right)$, can be formed without specification of flowdependent mixing length scale $\lambda$ [7]. Turbulence kinetic energy $(k)$ is the mean kinetic energy per unit mass associated with eddies in turbulent flow. Physically, the turbulence kinetic energy is characterized by measured root-mean-square (rms) velocity fluctuations. In the Reynolds-averaged Navier Stokes equations, the turbulence kinetic energy can be calculated based on the closure method, i.e. a turbulence model. Generally, the turbulent kinetic energy can be quantified by the mean of the turbulence normal stresses:

$k=\frac{1}{2}\left\{\overline{\left(u_{x}\right)^{2}}+\overline{\left(u_{y}\right)^{2}}+\overline{\left(u_{z}\right)^{2}}\right\}$

$k$ can be produced by fluid shear, friction or buoyancy, or through external forcing at lowfrequency eddy scales (integral scale). Turbulence kinetic energy is then transferred down the turbulence energy cascade, and is dissipated by viscous forces at the Kolmogorov scale. This process of production, convective transport and dissipation as modeled for $k$ transport balance in the two-equation turbulence model can be expressed as:

$\frac{D k}{D t}=\nabla \cdot\left(\frac{v_{T}}{\sigma_{k}} \nabla k\right)+P-\varepsilon$

The three other terms, $-D k / D t, P$, and $\varepsilon$, are in closed form given the turbulent-viscosity hypothesis.

Turbulence consists of high levels of fluctuating vorticity. At any instant, vortical motion called eddies are present in the flow. These eddies range in size from the largest geometrical scales of the flow; such as, tank diameter, down to small eddies where molecular diffusion dominates. The eddies are continuously evolving, and the superposition of their induced motions leads to the fluctuating waves. In this situation, turbulent kinetic energy is dissipated from the largest eddies down to the smallest through a process called energy cascade. In order to maintain the turbulence, a constant supply of energy must be fed to the turbulent fluctuations at the largest scales from the mean motions, where it is driven by a jet pump or mechanical agitator. Thus, turbulent energy dissipation rate $\varepsilon$ is viewed as the energy-flow rate in the cascade, and it is determined by the large-scale motions, independent of the viscosity at high Reynolds number. Consequently, the transport equation for $\varepsilon$ is best considered as being entirely empirical. That is, 
$\frac{D \varepsilon}{D t}=\nabla \cdot\left(\frac{v_{t}}{\sigma_{\varepsilon}} \nabla \varepsilon\right)+C_{1}\left(\frac{\varepsilon}{k}\right) P-C_{2} \frac{\varepsilon^{2}}{k}$

The governing equations to be solved for the present work are composed of one continuity equation, three momentum equations for the three component directions $(x, y$, and $z$ directions), and two constitutive equations for the turbulence descriptions. The detailed descriptions for the governing equations and computational methods are provided in the previous work [3].

When a tracer species, such as acid material, is added to the tank during mixing operations before transfer of the tank contents, the added species is transported over the tank domain by the continuous fluid motion driven by the pump. The modeling calculations for the mixing time require the balance equation of tracer species. The species balance equation is given by

$\frac{\partial \rho Y_{v}}{\partial t}+\nabla \cdot\left(\rho \vec{v} Y_{v}\right)=-\nabla \cdot \vec{J}_{v}+S_{v}$

$Y_{v}$ is local mass fraction of tracer species in the continuous fluid. $\vec{J}_{v}$ is diffusion flux of tracer species. $S_{V}$ in the equation is a source term of tracer species added to the tank fluid due to the injection of the acid from the top of tank. The diffusion flux of tracer under turbulent fluid flow is computed by

$\vec{J}_{v}=-\left(\rho D_{v}+\frac{\mu_{t}}{S c_{t}}\right) \nabla Y_{v}$

$D_{v}$ is molecular diffusion coefficient of tracer in the continuous fluid medium. Typical molecular diffusion coefficient of liquid species in the liquid domain is about $1 \times 10^{-9}\left(\mathrm{~m}^{2} / \mathrm{sec}\right)$, which is much smaller than gas species.

The governing equations described above are solved over the entire tank domain as shown in Fig. 3. For the calculations, the domain was meshed by a hexahedral meshing technique. The number of mesh nodes for the slab domain was established as about $1.2 \times 10^{5}$ nodes. Figure 4 shows three-dimensional computational volume meshes for the domain including the pipe structures.

A mixing model of the tank configuration was set up with the return path reflecting the actual tank configuration as defined in engineering drawing [1]. The modeling domain and configurations for the tank with the loop structures of elbow pipe and exit pipe are shown in Fig. 3. As shown in the figure, a discharge elbow connected with vertical pipe is located near the tank bottom 0.25 inches above the tank floor, and the exit flow leaves the tank through the 1 inch pipe connected to the bottom side of the slab tank. In this case, the heavier fluid, Fluid 1, was an acid of 1.11 specific gravity and $1 \mathrm{cp}$ viscosity, and total volume Fluid 1 settled on tank floor was about 12 liters for the initial period. In this period, total volume 60 liters of the lighter fluid, Fluid 2, are placed on the top of Fluid 1 inside the slab tank, NT-21, as shown in Fig. 5. Fluid properties for both of the two fluids to be mixed are shown in Table 1. Based on the initial species settings of Fig. 5 and the modeling boundary conditions of Table 2, the transient species profile of fluid species Fluid 2 was then calculated and observed for estimation of the mixing time. 
The modeling results were benchmarked against the literature data and the previous SRNL test results [2]. The validated model was applied for the modeling calculations to estimate the mixing time for nominal operating conditions of a thin slab tank, NT-21.

Table 2. CFD modeling conditions used for the mixing analysis

\begin{tabular}{|c|c|c|c|}
\hline \multirow{6}{*}{$\begin{array}{l}\text { Nominal } \\
\text { case }\end{array}$} & \multirow{3}{*}{$\begin{array}{l}\text { Fluid } 1 \\
\text { (2.7 M acid) }\end{array}$} & Density & $1108 \mathrm{~kg} / \mathrm{m}^{3}$ \\
\hline & & Viscosity & $1 \mathrm{cp}$ \\
\hline & & Volume of fluid & 12 liters \\
\hline & \multirow{3}{*}{$\begin{array}{l}\text { Species fluid to be mixed } \\
\text { (Fluid 2: Water) }\end{array}$} & Density & $994 \mathrm{~kg} / \mathrm{m}^{3}$ \\
\hline & & Viscosity & $1 \mathrm{cp}$ \\
\hline & & Volume of fluid & 60 liters \\
\hline \multirow{6}{*}{$\begin{array}{l}\text { Sensitivity } \\
\text { case }\end{array}$} & \multirow{3}{*}{$\begin{array}{l}\text { Fluid } 1 \\
\text { (8 M acid) }\end{array}$} & Density & $1268 \mathrm{~kg} / \mathrm{m}^{3}$ \\
\hline & & Viscosity & $1.4 \mathrm{cp}$ \\
\hline & & Volume of fluid & 12 liters \\
\hline & \multirow{3}{*}{$\begin{array}{l}\text { Species fluid to be mixed } \\
\text { (Fluid 2: } 1.5 \mathrm{M} \text { acid) }\end{array}$} & Density & 1075 kg/m ${ }^{3}$ \\
\hline & & Viscosity & $1 \mathrm{cp}$ \\
\hline & & Volume of fluid & 60 liters \\
\hline \multicolumn{3}{|c|}{ Pipe diameter (shown in Fig. 1) } & $\begin{array}{l}\text { - } 1 \text { inch for exit pipe } \\
\text { - } 0.402 \text { inches for inlet pipe }\end{array}$ \\
\hline \multicolumn{3}{|c|}{ Circulation flowrate } & 5.7 liters/min \\
\hline \multicolumn{3}{|c|}{ Velocity for incoming flow } & $1.16 \mathrm{~m} / \mathrm{sec}$ \\
\hline
\end{tabular}




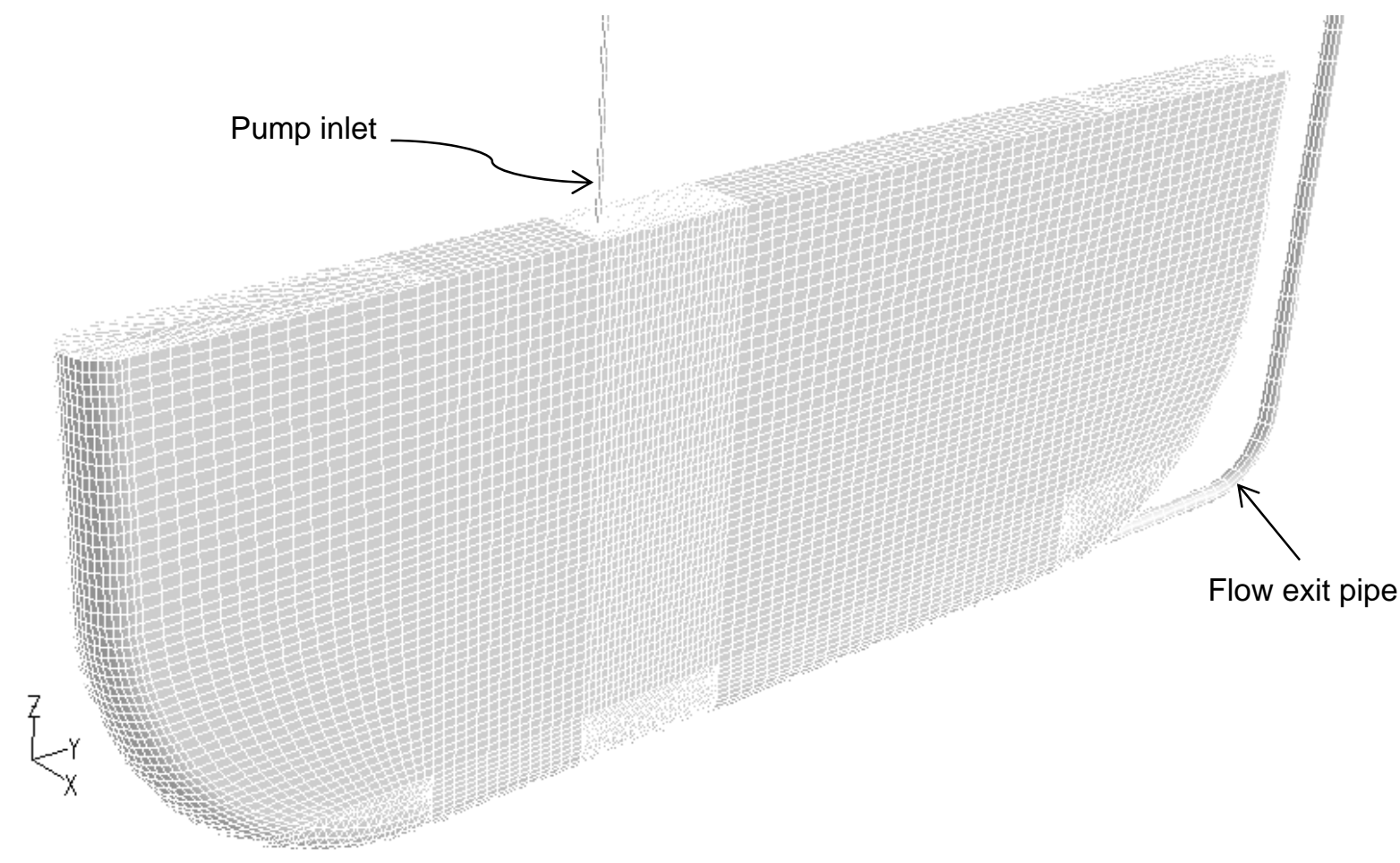

Figure 4. Computational meshes for the NT-21 tank mixing analysis ( $1.2 \times 10^{5}$ meshes)

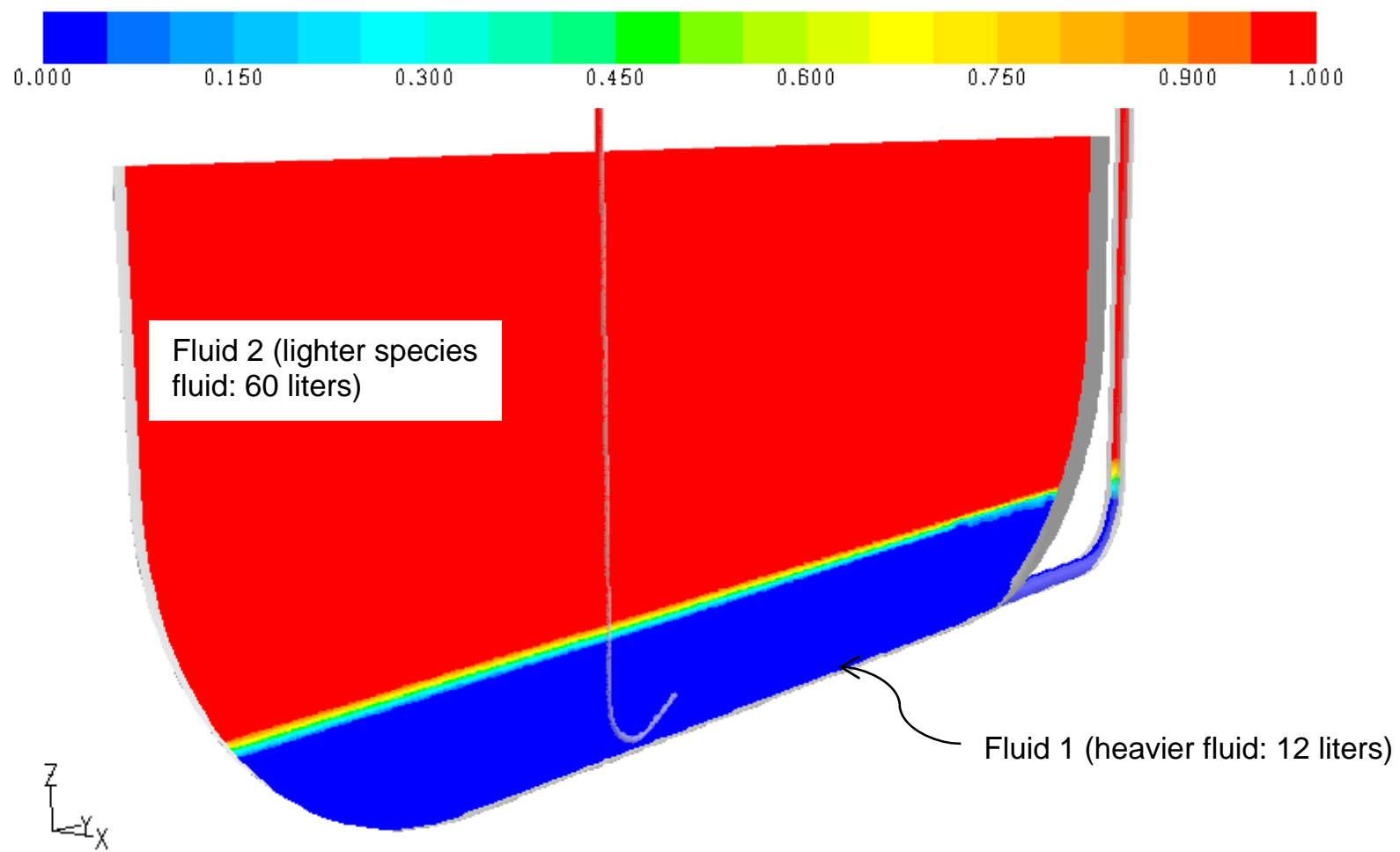

Figure 5. Initial mass fractions of the species and bulk fluids inside the NT-21 tank used for the mixing analysis 


\subsection{Results and Discussions}

\subsection{Results for Hydraulic Calculations}

Based on the modeling assumptions and governing equations provided in section 2.1 along with physical dimensions and fluid properties as shown in Table 1, the calculations have been made by using Microsoft Excel spread sheet to evaluate the slurry flowrate driven by the $45 \mathrm{ft}$ pump head (or $20 \mathrm{psi}$ ) for different operating conditions.

The calculations were based on the slurry flow assumption without air entrainment and the piping layout information as shown in Fig. 1. Total pipe lengths are about 255 inches for the circulation loop of NT-21 and about 670 inches for the circulation loop of NT-41 as provided in Table 1. Two cases were considered for the circulation loops connected to two tanks, NT21 and NT-41. One case is for the T-junction valve (Valve 1 in Fig. 1) closed to allow the fluid flow to be recirculated through NT-21 and to be performed for the species mixing of NT21 contents, while the other is for the valve open to allow the mixed slurry fluid to be transferred to NT-21.

The calculation results demonstrate that pump head pressure of 20 psi recirculates about 5.6 liters/min (Ipm) flowrate through 0.131 -inch orifice when a valve connected to NT-41 is closed. In case of the valve open to NT-41, the solution flowrates to NT-21 and NT-41 are found to be about $0.5 \mathrm{lpm}$ and $5.2 \mathrm{lpm}$, respectively. The calculations are based on the slurry density of $1.1778 \mathrm{gm} / \mathrm{cc}$. The results for two different orifice sizes of 0.131 " and 0.25 " are summarized in Table 3.

Table 3. Results for the modeling cases considered for the hydraulic analysis

\begin{tabular}{|c|c|c|c|c|}
\hline \multirow{2}{*}{$\begin{array}{c}\text { Modeling } \\
\text { cases }\end{array}$} & $\begin{array}{c}|c| \\
\text { Orifice size } \\
\text { (inches) }\end{array}$ & $\begin{array}{c}\text { Valve 1* } \\
\text { open or close }\end{array}$ & $\begin{array}{c}\text { Return flow } \\
\text { to NT-21 }\end{array}$ & $\begin{array}{c}\text { Flowrate to } \\
\text { NT-41 }\end{array}$ \\
\cline { 2 - 5 } Case-1 & 0.131 & close & 5.6 & 0 \\
\hline Case-2 & 0.131 & open & 0.5 & 5.2 \\
\hline Case-3 & 0.25 & close & 17.9 & 0 \\
\hline Case-4 & 0.25 & open & 13.7 & 5 \\
\hline
\end{tabular}

Note:*Valve 1 location shown in Fig. 1

\subsection{Results for Mixing Performance Calculations}

Using the CFD approach described above, FLUENT modeling calculations were made to numericaly simulate the mixing operation. The transient modeling calculations starting with another set of species balance equation in addition to the continuity, momentum, and two 
turbulence equations were performed for the time estimate to mix the tank contents that consist of two different miscible acid solutions in NT-21. In this approach, the transient calculations were started from the initial species distribution as shown in Fig. 5 along with the modeling conditions of Table 1 for the discretized computational domain as shown in Fig. 4. A transient run was started with 5.7 liters/min recirculation flowrate jetted into the tank solution through the 0.402 inch pipe, and run until the lighter species, Fluid 2, was mixed with the Fluid 1 species in a homogeneous way within 99\%. In this case, the Fluid 2 species has properties of 1.0 specific gravity and $1.0 \mathrm{cp}$ viscosity, and total volume injected through the discharge pipe was 5.7 liters every minute. The transient species profile for the lighter solution of Fluid 2 was calculated and observed to estimate the time to get homogeneously mixed.

The benchmarking tests are chosen as two typical areas representing the turbulent flow dissipations, and flow pattern behavior since these two phenomena are closely related to the miscible fluid mixing and species dispersion mechanisms within the bulk fluid space of the tank with flow recirculation. Both of the benchmarking areas are closely related to the mixing times of the miscible tank contents, and the spread behavior of the injected species. The detailed results are provided in the subsequent section.

\section{Literature Benchmarking Results for Mixing}

A benchmarking model of the Tank A configuration shown in Table 4 was developed with the return path reflecting the actual tank configuration as described by Grenville and Tilton [5]. The model configuration is shown in Figure 6. As shown in the figure, a jet pump with $42.6^{\circ}$ upward angle is located at the tank bottom, and the jetted flow returns to the pump through the tank bottom. Based on this model, a two-step method was applied to estimate the blending time for benchmarking of Grenville's experimental work. In this approach, the transient mixing calculations were started from the fully developed flow distribution of the first step runs as initial conditions. The second step simulated the mixing tests performed by Grenville and Tilton [5]. Figure 7 shows the fully developed flow patterns established by the first step. The second step was a transient calculation for a contaminant species started from the fully developed condition of the first run in which the species was injected for 10 seconds into the inlet jet. In this case, the species fluid was an acid with a 1.14 specific gravity and a $1.16 \mathrm{cp}$ viscosity, where the total volume injected through a $10 \mathrm{~mm}$ hole was approximately 0.21 gallons for an initial period of 10 seconds. Detailed test configurations and the computational domain of the Tank A system are shown in Figure 6 . The transient species profile was then calculated and observed. Figure 8 shows Lagrangian flow path lines from the pump inlet to the tank exit for fully developed flow circulation inside the tank during the mixing period.

For comparison of the species blending time with flow evolution time, a transient run with no species addition was started from stagnant tank fluid conditions and run until fully developed steady state flow patterns were established. The results of Table 4 are consistent with the results shown in Figure 9. Comparison of transient snapshots between species concentration and flow patterns at a vertical central plane crossing the pump nozzle exit is made in Figure 15, indicating that the tank blending time is shown to be about 33 seconds, which is in agreement with Grenville's measured results of 32 seconds to within about 3\%. In the figure, species concentration was non-dimensionalized in terms of equilibrium species concentration of $3.02 \times 10^{-4}$. The results show very clearly that the injected contaminant species follows the velocity profile and that the propagation of the contaminant species develops over the same time period as both the bulk flow and the eddy flow patterns. From 
the previous results [6], the benchmarking results for blending time are shown in Fig. 10. These results demonstrated that the CFD models predicted the test results for a range of jet $U_{0} d_{0}$ operating conditions within about $20 \%$.

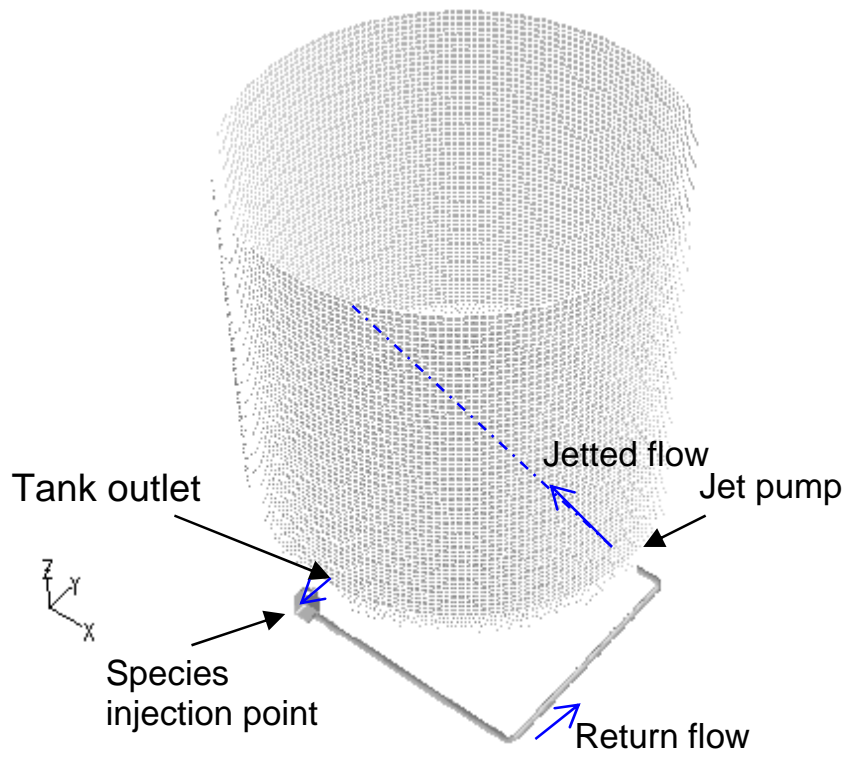

Figure 6 Tank A, geometry for the demonstration runs based on two different approaches of transient flow pattern and species transport calculations

Table 4. Test conditions and literature mixing times [Ref. 3] for transient CFD calculations

\begin{tabular}{|c|c|c|c|c|c|c|c|}
\hline Tank & $\begin{array}{c}D \\
\text { (Tank dia.) }\end{array}$ & $\begin{array}{c}h_{l} \\
\text { (liquid } \\
\text { height) }\end{array}$ & $\begin{array}{c}\text { Inclination } \\
\text { angle of Jet* }\end{array}$ & $\begin{array}{c}d_{o} \\
\text { (jet dia.) }\end{array}$ & $\begin{array}{c}U_{o} \\
\mathrm{~m} / \mathrm{se} \\
\mathrm{c}\end{array}$ & $R e_{j e t}$ & $\begin{array}{c}\text { Mixing time by } \\
\text { G-T correlation } \\
{[5]}\end{array}$ \\
\hline Tank A & $1.68 \mathrm{~m}$ & $1.55 \mathrm{~m}$ & $42.6^{\circ}$ & $\begin{array}{c}26.1 \\
\mathrm{~mm}\end{array}$ & 19.8 & 516,780 & $32 \mathrm{sec}$. \\
\hline
\end{tabular}

Note: * Jet is located at the corner of tank bottom as shown in Figure 5. 
SRNL-STI-2014-00513

Revision 0
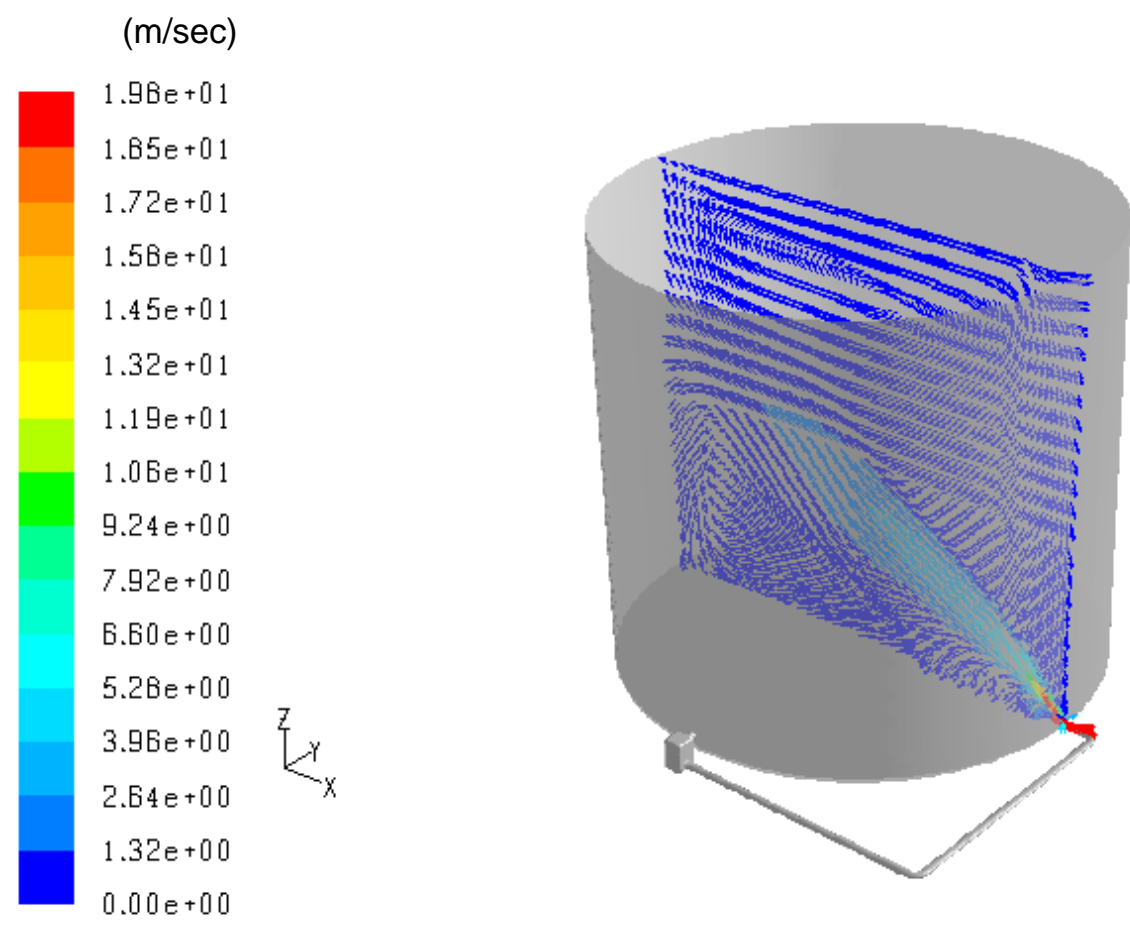

Figure 7. Fully developed flow patterns used as the initial flow conditions for the transient transport calculations using tracer species

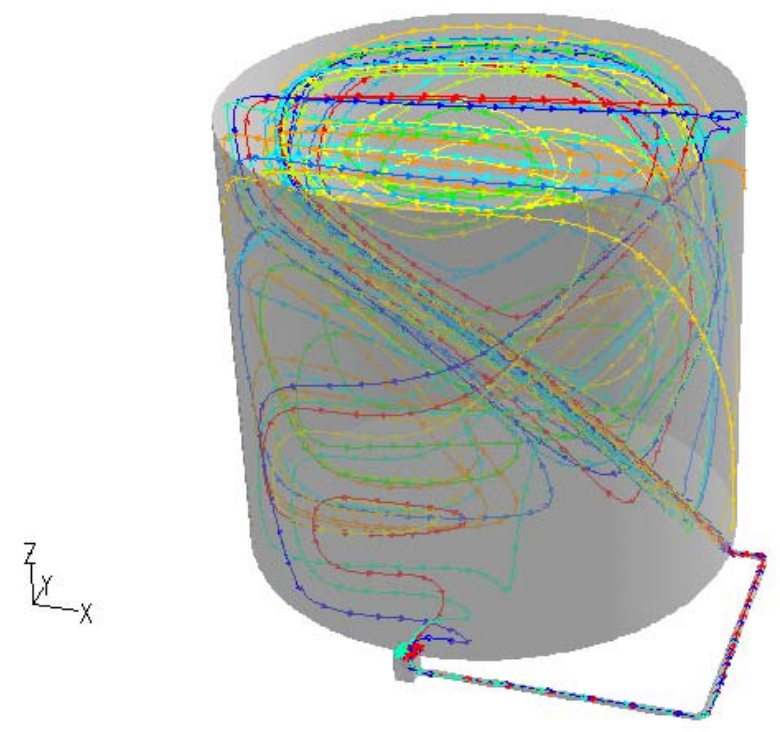

Figure 8. Lagrangian flow path lines from jet inlet to tank exit for fully developed flow circulation inside a tank during blending 
(Nondimensional species conc.)*

0
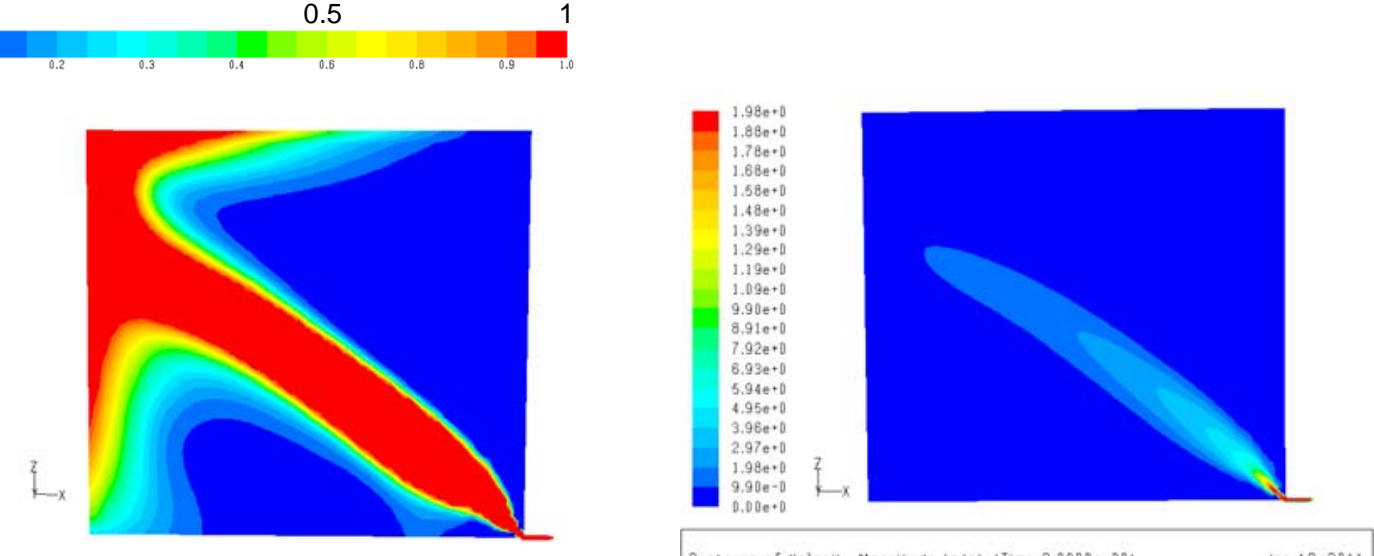

Contours of Velocity Magnitude $(\mathrm{m} / \mathrm{s})$ (Time $-3,0000 \mathrm{f} e+000)$ Jan 18,2011

$(\mathrm{t}=3 \mathrm{sec})$

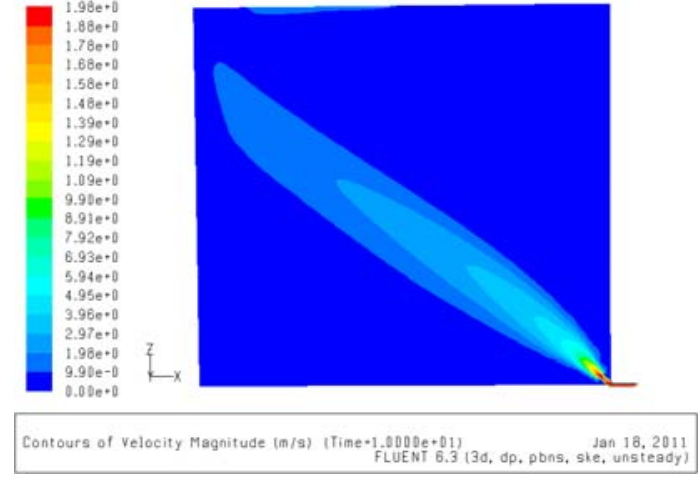

$(\mathrm{t}=10 \mathrm{sec})$

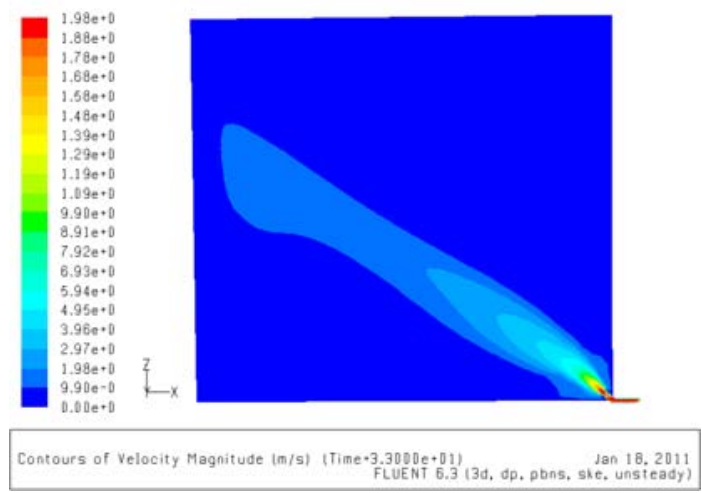

( $t=33$ sec: blending time within 95\% homogeneity)

Figure 9. Comparison of transient time snapshots for flow patterns of species concentration at vertical central plane through the pump nozzle center line (*Nondimensionalized by equilibrium species concentration of $3.02 \times 10^{-4}$; literature blending time results $=32$ seconds) 


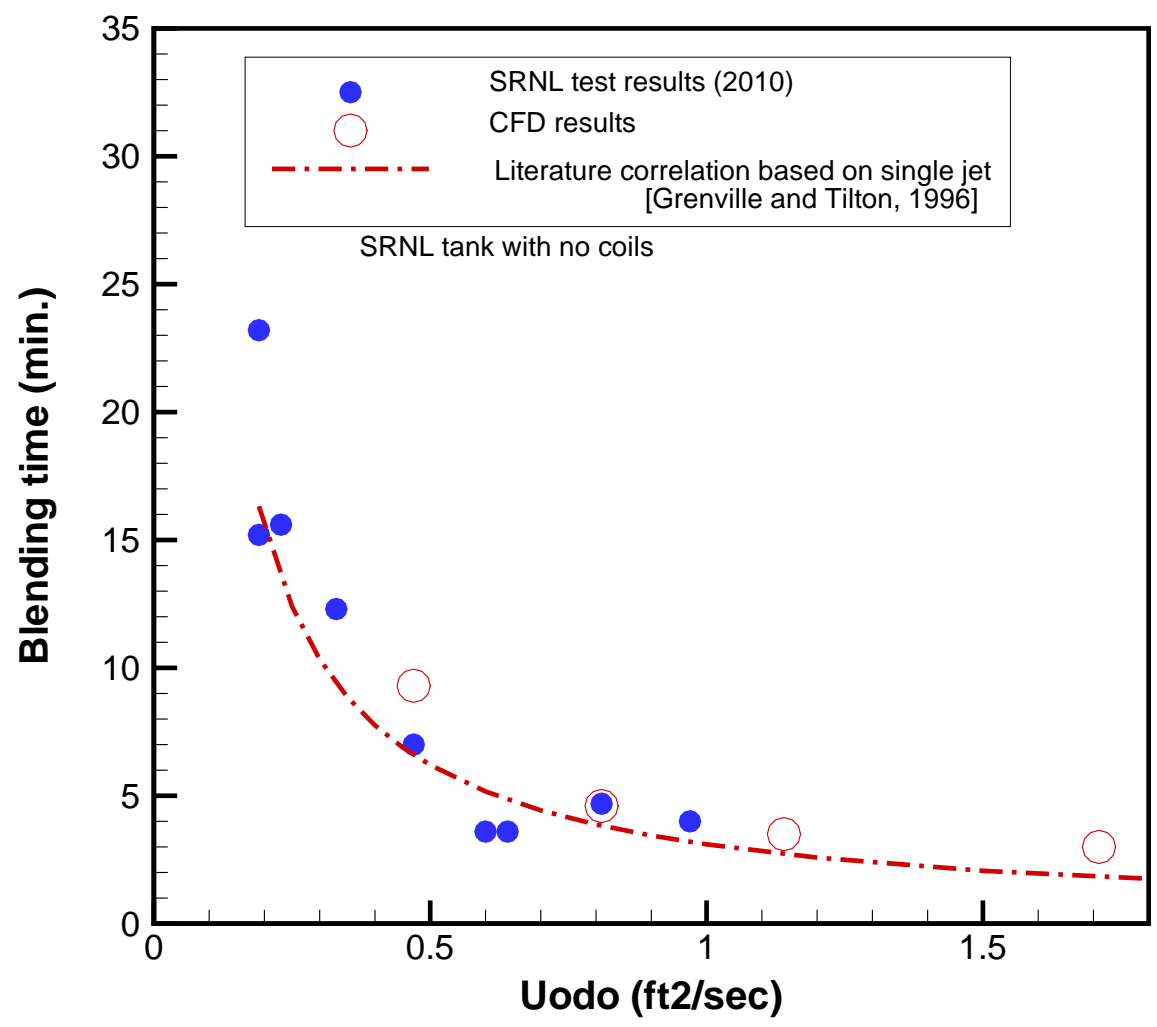

Figure 10. Benchmarking results of theoretical tank blending time compared to experimental test results [6]

\section{$\underline{\text { Performance Results for Mixing Calculations in NT-21 Tank }}$}

Based on the validated CFD model, the current work consists of two main goals. One goal is to quantify the mixing operation time that will adequately blend and mix two miscible liquids to obtain a uniform composition in the tank with a minimum level of nonuniform species contents. The other is to verify adequacy of 1.5 hours of pump recirculation for tank species to be well mixed in HB-Line tank, NT-21.

The CFD modeling calculations were performed to determine mixing time for potential operating conditions as shown in Table 2. The calculations were performed two cases as shown in the table. One is the nominal case for the tank solutions consisting of the existing $2.5 \mathrm{M}$ acid solution and incoming water species. The other case is for the sensitivity run consisting of two acid solutions of $8 \mathrm{M}$ existing solution and $1.5 \mathrm{M}$ incoming species. For the performance analysis, the modeling calculations were based on the 5.7 liters/min pump recirculation to evaluate the mixing time in NT-21. The results show that the maximum speed is about $1.1 \mathrm{~m} / \mathrm{sec}$ at inlet of the pipe located at about 1.5 inches above the tank floor, corresponding to 5.7 liters/min circulation flowrate. In this case, the inlet nozzle is installed at a distance of 22.25 inches from the wider side wall and at the center of the narrower side of the slab tank as shown in Fig. 2. 
Figure 11 shows the circulation flow patterns at 90 minutes' transient time for the center plane of the slab tank. The corresponding flow velocity distributions and turbulent intensities at the center plane of the slab tank are shown in Figs. 12 and 13, respectively.

Turbulence intensity can be used as an indicator of local mixing. The turbulence intensity $I$ is defined as the ratio of the root-mean-square of the velocity fluctuations to mean flow velocity. That is,

$I=\frac{\sqrt{\frac{1}{3}\left(u^{\prime 2}+v^{\prime 2}+w^{\prime 2}\right)_{\text {avg }}}}{V} \approx 0.8165 \frac{\sqrt{k}}{V}$

In Eq. (19) the turbulence intensity is proportional to the square root of the turbulent kinetic energy $k$ for a given mean fluid velocity. The results shown in Figs. 12 and 13 indicate that the velocity reduction rate along the discharge direction increases with increasing turbulence intensity. This is mainly related to the increased radial dispersion of fluid momentum which leads to diminished axial velocity of the nozzle discharge flow. As shown in Fig. 13, the turbulent velocity due to flow fluctuation is less than about 10 percentage of local mean velocity, resulting in rapidly dissipating convective flow field.

The snapshots of the transient mass fractions for the modeling conditions of Table 2 are shown in Fig. 14. As shown in the figure, the lighter species is stratified during the mixing period since convective motion is not large enough to overcome the gravity along the vertical depth of the tank solution. As shown in Fig. 15, a mixing time of 90 minutes for the nominal case will be required when two miscible fluids are mixed by one recirculation pump. The calculation results demonstrate that when a pump recirculates the solution volume of 5.7 liters every minute out of the total volume of 72 liters in the NT-21 tank containing two acid solutions of $2.7 \mathrm{M}$ and $0 \mathrm{M}$ concentrations (i.e., water), a minimum mixing time of 1.5 hours is adequate for the tank contents to get adequately mixed. The sensitivity results for the tank contents of $8 \mathrm{M}$ existing solution and $1.5 \mathrm{M}$ incoming species show that the mixing time takes about 2 hours to get the solutions mixed. Table 5 summarizes the results of the nominal and sensitivity cases. 
SRNL-STI-2014-00513

Revision 0

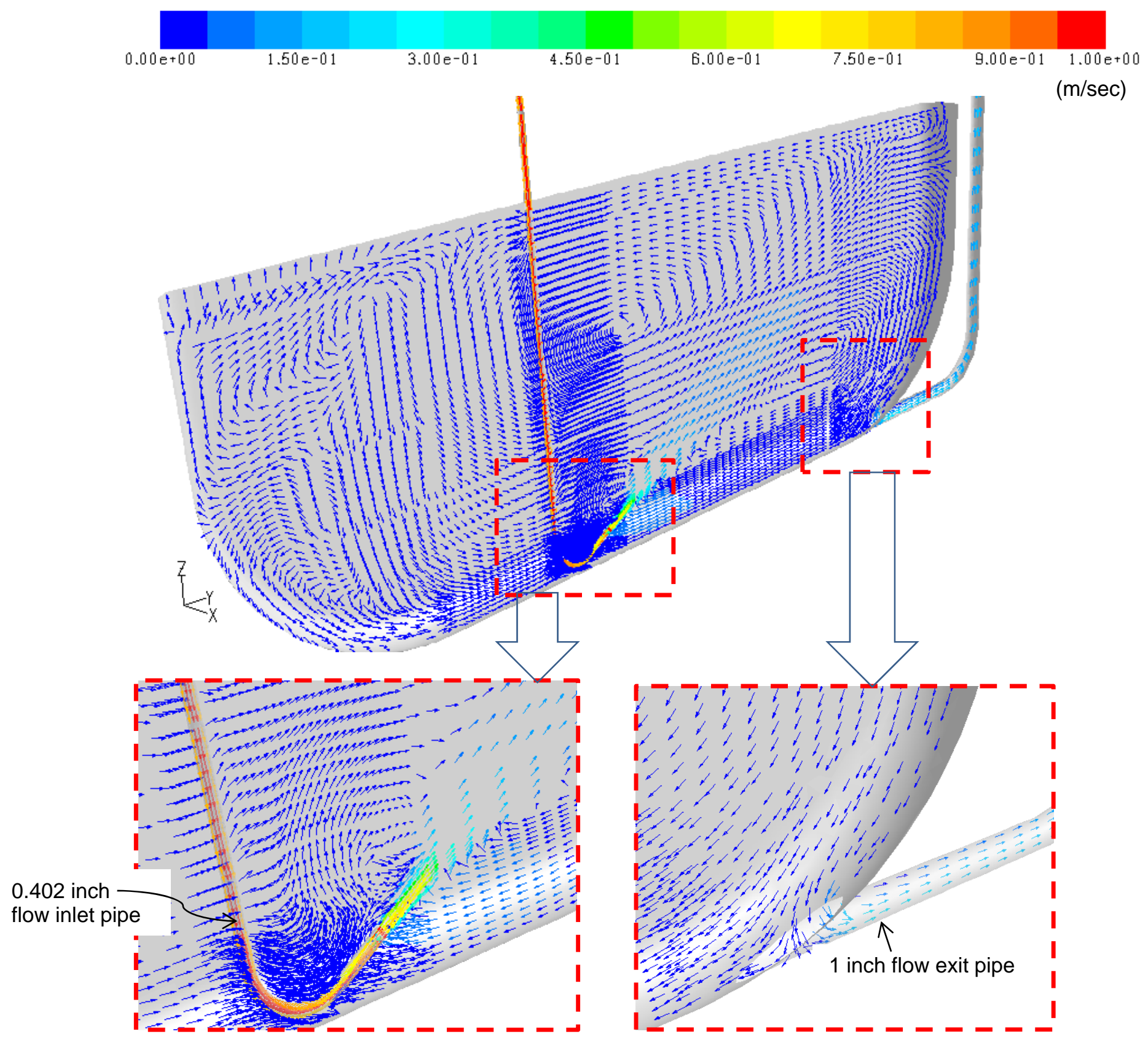

Figure 11. Circulation flow patterns near flow inlet and exit regions at $90 \mathrm{~min}$. transient time 


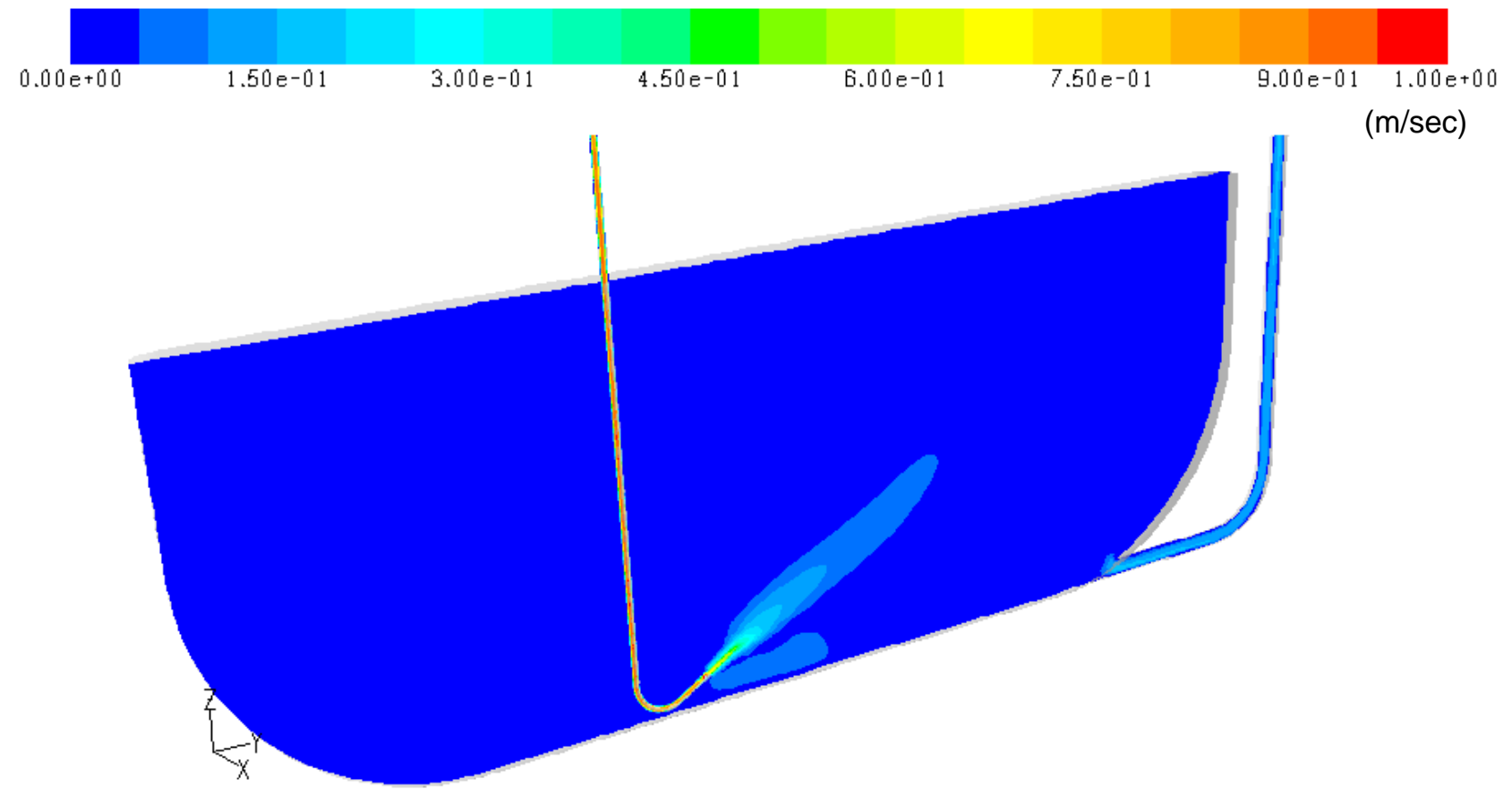

Figure 12. Flow velocity distributions for the central plane at $90 \mathrm{~min}$. transient time

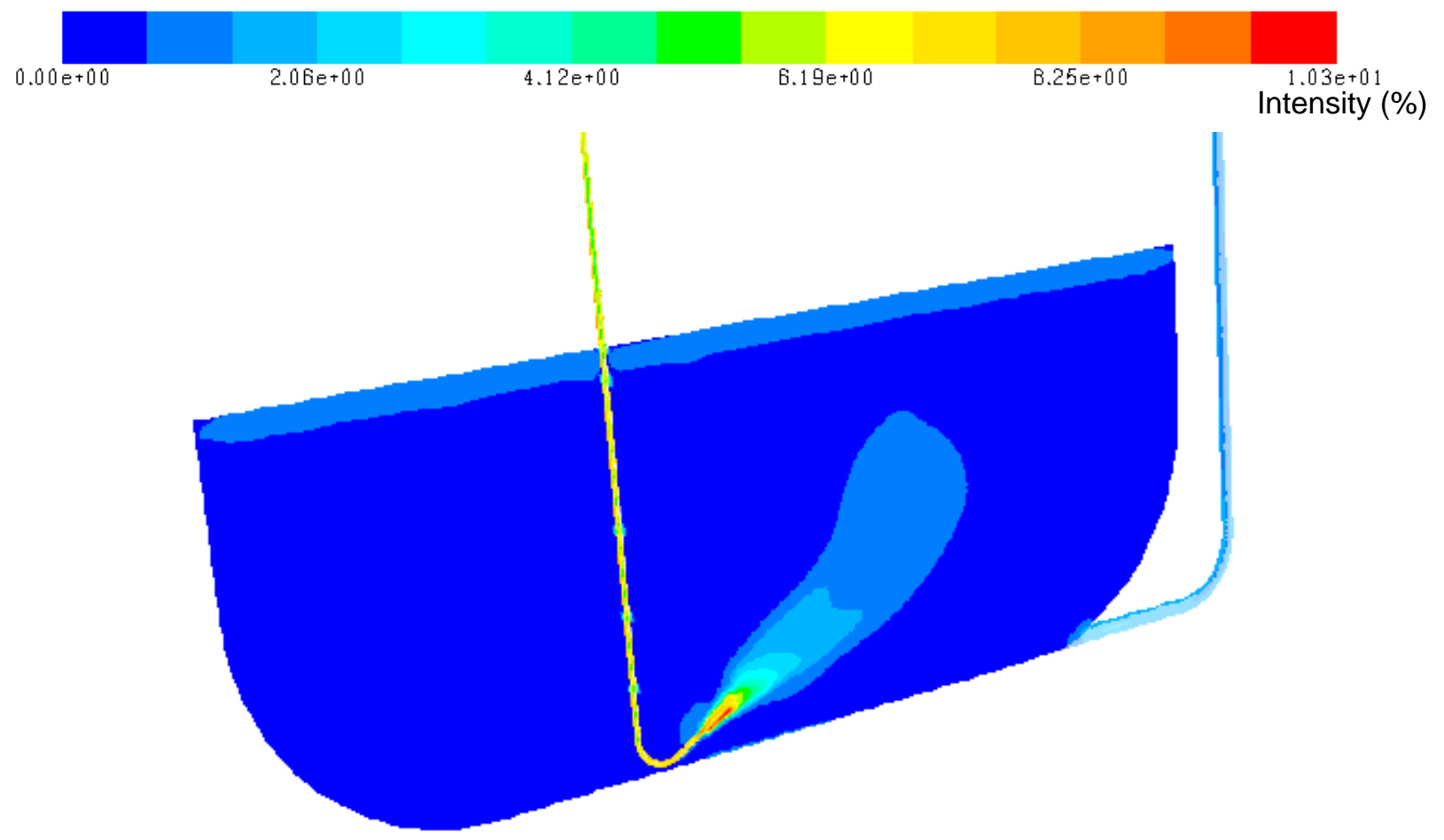

Figure 13. Flow turbulent intensity distributions for the central plane at $90 \mathrm{~min}$. transient time 

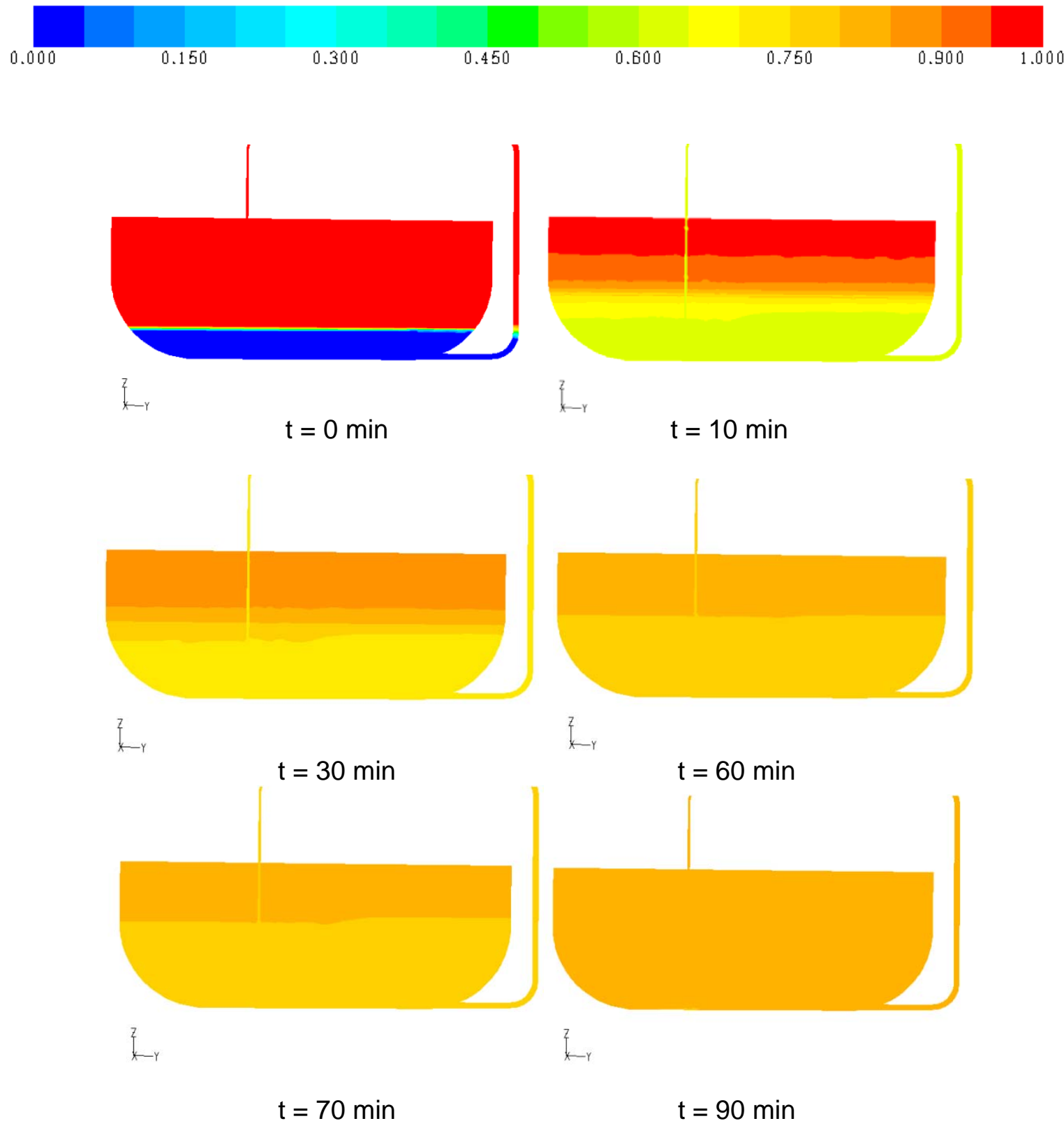

Figure 14. Transient non-dimensional mass fractions for Nominal case. 


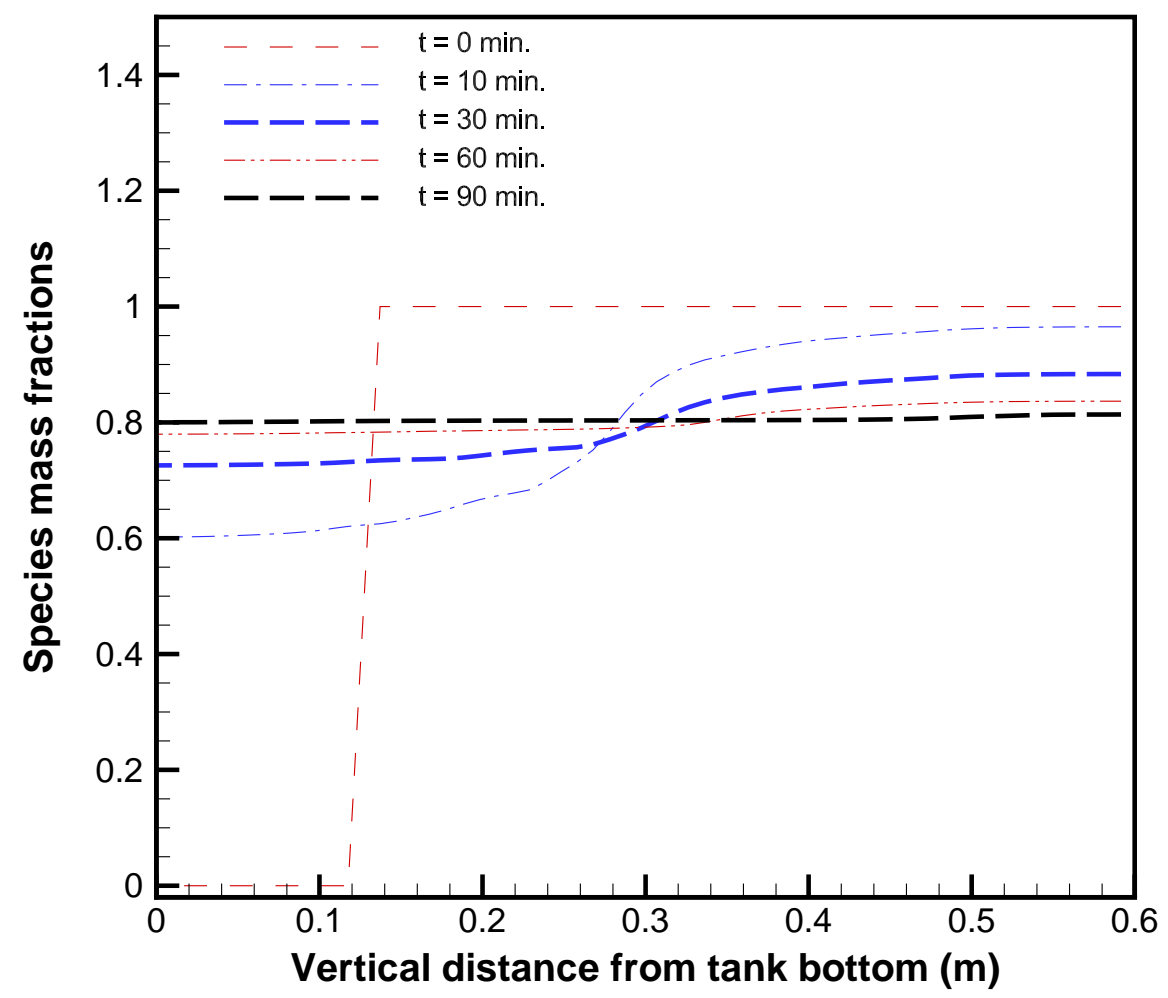

Figure 15. Transient species mass fractions during the mixing period (Nominal case).

Table 5. CFD modeling results used for the mixing analysis

\begin{tabular}{|c|c|c|}
\hline Case & Molarities & Mixing time (min.) \\
\hline \multirow{2}{*}{ Nominal case } & $\begin{array}{c}\text { Fluid 1 } \\
(2.7 \text { M acid) }\end{array}$ & 90 \\
\cline { 2 - 3 } & $\begin{array}{r}\text { Species fluid to be mixed } \\
\text { (Fluid 2: Water) }\end{array}$ & \multirow{2}{*}{120} \\
\hline \multirow{2}{*}{ Sensitivity case } & $\begin{array}{r}\text { Fluid 1 } \\
\text { (8 M acid) }\end{array}$ & \multicolumn{2}{|c|}{120} \\
\cline { 2 - 3 } & $\begin{array}{c}\text { Species fluid to be mixed } \\
\text { (Fluid 2: 1.5 M acid) }\end{array}$ & \\
\hline
\end{tabular}




\subsection{Summary}

The hydraulic results demonstrate that a pump head pressure of 20 psi recirculates about 5.6 liters/min (Ipm) flowrate through the existing 0.131 -inch orifice when a valve connected to NT-41 is closed. In case of the valve open to NT-41, the solution flowrates to HB-Line tanks, NT-21 and NT-41, are found to be about $0.5 \mathrm{lpm}$ and $5.2 \mathrm{lpm}$, respectively.

The modeling calculations for the mixing operations of miscible fluids contained in NT-21 were performed by taking a three-dimensional Computational Fluid Dynamics (CFD) approach. The CFD modeling results were benchmarked against the literature results [5] and the previous SRNL test results [2] to validate the model. Final performance calculations were performed by using the validated model to quantify the mixing time for the HB-Line tank. The mixing study results for the NT-21 tank show that, for the nominal case modeled, the mixing time adequate for the blending of tank contents is at least 90 minutes when nominal flowrate of 5.7 liters/min is recirculated through the tank. The sensitivity results for the tank contents of $8 \mathrm{M}$ existing solution and $1.5 \mathrm{M}$ incoming species show that the solution mixing takes about 2 hours to get the solutions mixed.

\subsection{References}

1. Drawing \# for PV 180691, 100 Liter Hold TK

2. S. Y. Lee, R. A. Leishear, and M. R. Poirier, "Tank 21 and Tank 24 Blend and Feed Study: Blending Times, Settling Times, and Transfers", SRNL-STI-2012-00306, May 2012.

3. S. Y. Lee, R. A. Dimenna, R. A. Leishear, and D. B. Stefanko, "Analysis of Turbulent Mixing Jets in a Large Scale Tank", ASME Journal of Fluids Engineering, Volu 130, Number 1, 2008, p. 011104.

4. ANSYS FLUENT 6.3, September 2010.

5. R. K. Grenville, and J. N. Tilton, "A New Theory Improves the Correlation of Blend Time Data from Turbulent Jet Mixed Vessels", Trans. Inst. of Chem. Eng., Vol. 74, Part A., 1996, pp. 390-396.

6. S. Y. Lee and B. W. Armstrong, "SDI CFD Modeling Analysis", SRNL-STI-2011-00025, April 2011

7. Jones, W. P. and Launder, B. E., 1972, "The Prediction of Laminarization with a TwoEquation Model of Turbulence", Int. J. of Heat Mass Transfer, vol. 15, pp. 301-314, 1972. 